Propositions and Thoughts towards

a Comparative History of the

Americas: Jack Greene's essay.

\title{
Considerações e reflexões para uma história comparada das Américas: a respeito do artigo de Jack $P$. Greene.
}

\section{Marco Antônio Pamplona}

Professor nos Departamentos de História da PUC-Rio e da Universidade Federal Fluminense

\begin{abstract}
Resumo
A partir da discussão das reflexões encaminhadas por Jack Greene no ensaio, "Reformulando a identidade inglesa na América britânica colonial: adaptação cultural e experiência provincial na construção de identidades corporativas", o presente artigo desenvolve considerações para uma história comparada nas Américas. Analisa os argumentos apresentados sobre: (a) o mundo colonial atlântico e as dificuldades conceituais que predominam nas histórias nacionais; (b) a dinâmica dos impérios - os processos de "etnização" em marcha e a construção de novas polities nas colônias; (c) a manutenção de valores britânicos nas identidades provinciais, no periodo que vai de 1760 à independência; e (d) a continuidade das identidades corporativas nas antigas provincias, depois de tornadas estados ou polities republicanas, no período nacional. É a aceitação desta última afirmação, a que nos permitirá falar, ainda por algum tempo (ao menos até o seccionalismo dos anos de 1840s ou 1850s) do Estado Federal Americano ainda como um compósito de identidades estaduais.
\end{abstract}

\begin{abstract}
By making use of the discussion of the main thoughts forwarded by Jack Greene in his essay "Reformulating Englishness: Cultural Adaptation and Provinciality in the Construction of Corporate Identity in Colonial British America", I focus on comparative history in the Americas. In this article, I analyze the author's main arguments regarding: (a) the Atlantic colonial world and the conceptual difficulties or handicaps that still pervade national histories; (b) the dynamics of the empires - the "ethnification" processes on the way and the building of new polities in the colonies; (c) the enduring of British values deeply rooted in the provincial identities, from the 1760s to independence; and (d) the continuity of the corporatist identities in the old provinces, turned states or republican polities in the national period. The agreement with this last statement will allow us to keep viewing the American Federal State (at least until the development of the seccionalist trends of the 1840s or 1850s) still as a composite of state identities.
\end{abstract}

\section{Palavras-chave}

revolução, Império britânico, Independência, Estados Unidos, identidade nacional, identidade regional

\section{Keywords}

revolution, British Empire, Independence, United States, national identity, regional identity 
Jack P. Greene, "Reformulando a identidade inglesa na América britânica colonial: adaptação cultural e a experiência provincial na construção de identidades corporativas", In: Revista Almanack Braziliense, N.4, novembro de 2006, p.17

2

0 limite apontado para os anos 1830s, devese ao fato do já envolvimento dos estados com os temas seccionalistas, criando aos poucos, ao longo das duas décadas seguintes, também identidades regionais que passariam a intervir cada vez mais fortemente num debate nacional, crescentemente redefinido pela tensão NorteSul, anunciando uma crise política sem precedentes, a qual o Compromisso de 1850 não conseguiu evitar.
Com seu excelente artigo, Jack Greene nos oferece uma série de importantes indagações a respeito da natureza da América colonial britânica e do papel das províncias como entidades corporativas as mais significativas para a sua dinâmica.

Seu argumento fundamental é o de que, com o advento da independência e o início de um sistema de governo nacional americano, as antigas províncias, transformadas em estados republicanos, continuaram representando os loci mais importantes da autoridade. Afinal, havia sido nelas, nas provincias, que homens e mulheres partilharam entre si, para além da continuação de uma identificação cultural com uma idealizada identidade nacional britânica, também os primeiros elementos de uma identidade distintiva criada ao longo das primeiras gerações de colonos nas Américas?

Com o advento dos estados, criados a partir dessas mesmas antigas polities coloniais, esta identificação e identidades mencionadas se fariam continuar - especialmente no período que vai de 1787 a $1830 s^{2}$ - e ditariam a dinâmica da vida política do jovem estado-nação até os anos de 1850s.

Adiantaremos, a seguir, qual será a ordem de apresentação dos nossos comentários ao texto de Greene. Optamos por agrupar as questões mais importantes a tratar em quatro conjuntos, cada qual referido às principais discussões desenvolvidas ou sugeridas pelo autor, ao tratar do seu tema maior.

Um primeiro conjunto de questões dirá respeito ao mundo colonial atlântico e às discussões conceituais suscitadas sempre que estabelecemos comparações entre as muitas Américas do início da era moderna.

Um segundo conjunto, um pouco mais extenso, refletirá sobre a dinâmica do império, como o uso da violência em relação aos colonos e colonizados é alternado com a prática de negociar autoridades. Os processos de "etnização" em marcha ganham relevo nesta discussão e, com eles, a construção de novas polities e de primeiras identidades corporativas coloniais.

Um terceiro, se ocupará da questão da manutenção dos valores britânicos nas identidades provinciais. Na particular conjuntura que se estendeu da Guerra dos 7 Anos à separação da metrópole, como podia ser explicada a contínua valoração da idéia de Englishness? Mais ainda, como definir o caráter da Revolução, a um só tempo radical e conservadora?

E, finalmente, um quarto conjunto de questões será reservado à discussão sobre a continuidade das identidades corporativas criadas pelas antigas províncias, depois tornadas estados ou polities republicanas, no periodo nacional: o Estado Federal Americano como compósito de identidades estatais (state rights $\mathrm{x}$ federalism); a força das identidades locais e dos estados de 1787 aos anos de 1830s-1840s; e, o desenvolvimento das novas identidades que passarão a apontar para o seccionalismo, nos anos de 1840s a 1860.

\section{Sobre o mundo colonial atlântico.}

Muito já se disse sobre a propriedade de se falar de um "broader Atlantic world" em formação desde os séculos XV e XVI. Mas, não nos custa lembrar o papel das relações de comércio, alianças políticas entre impérios e casamentos no mundo dinástico, e o seu sucesso no criar um contato estreito entre quatro continentes e reunir, ainda que de forma desigual, esses três grandes grupos da humanidade - europeus, ameríndios e africanos - numa verdadeira economia atlântica colonial. Por sua vez, as frotas do tesouro espanhol, o comércio de peles norte-americano e o tráfico atlântico de escravos, nunca estiveram desvinculados do quadro maior das explorações daquele início do que se convencionou chamar de modernidade européia e cujo alcance global chegou a abarcar os Oceanos Pacífico e Índico, e os lito- 
Thomas Benjamin, Timothy Hall and David Rutherford (eds.), The Atlantic World in the Age of Empire. NY: Houghton Mifflin Co., 2001.

Jack P. Greene, Op. Cit., p.7, nota 1.

5

Idem, p.8.

Na falta de espaço, remetemos para uma maior discussão do processo de "etnização" ou "etnificação" mencionado, ao artigo de Marco Pamplona e Maria Elisa Mäder, intitulado "0 nacionalismo nas Américas: um balanço historiográfico", a ser publicado em breve na Revista Historia (Instituto de Historia - PUC de Chile) em 2006/2007 [no prelo].

Jack P. Greene, Op. Cit., p.8 rais que os circundam. Como muitos autores atestam ${ }^{3}$, um conjunto considerável de pessoas e idéias atravessaram o Atlântico desde então - idéias monoteistas de cristãos diversos, judeus e muçulmanos, conflitos sectários e étnicos e até tolerâncias ocasionais -, formando nas Américas suas novas sociedades, desde o início multi-étnicas e multi-culturais.

Jack Greene, a partir desse quadro maior de referência, insiste em destacar a insuficiência do termo "primórdios da América colonial" ("early América") ainda em uso por boa parte da historiografia norte-americana, caracterizado, ademais, pela apropriação pouco crítica do termo América. A alternativa oferecida - colonial British America tem como objetivo a sua maior explicitação ou precisão. Jack Greene e Jack Pole cunharam essa expressão nos anos de 1980s ${ }^{4}$, referindo-se à British America (ou América britânica) como apenas uma das muitas "early modern Americas" (ou Américas do início da era moderna), ao lado das Américas Espanhola, Portuguesa, Francesa, Holandesa, Sueca, Dinamarquesa, Russa e, certamente, das incontáveis Américas indígenas. Reclama, assim, uma história mais compreensiva do periodo e, igualmente, a necessidade de se considerar a história de todas essas muitas áreas culturais - ou formações sociais, para recuperarmos uma antiga expressão que, certamente, contempla essa dimensão cultural. Segundo Jack Greene, em cada uma dessas áeras, a heterogeneidade cultural foi a norma. Por isso, analisar as tranformações operadas nas Américas durante a época moderna, implica, sobretudo, recuperar a importância das diferentes identificações nacionais e étnicas vigentes.

Em meio à mistura de povos, crenças e ethnies, esteve um número crescente de imigrantes europeus não-britânicos. Em suma, a incorporação de novas populações de descendências outras também marcou as distintas formações sociais da América Inglesa colonial do início da era moderna ${ }^{5}$. Os muitos processos de "etnização" ou "etnificação" postos em marcha a partir dos primeiros tempos da formação do mundo colonial atlântico, foram responsáveis, lado a lado com as desigualdades resultantes das conhecidas clivagens sociais, pelas enormes disparidades de poder inerentes à situação colonial moderna. Mais ainda, algumas dessas discrepâncias se prolongaram ou se fizeram continuar no momento seguinte de formação dos estadosnacão nas Américas independentes ${ }^{6}$.

\section{Sobre a dinâmica do império e a prática de negociar autoridades.} Greene lembra-nos em seu artigo o quão inconseqüente costuma ser a utilização, ainda hoje, daquelas certas oposições binárias e formas de raciocínio dicotômicas que marcaram a reflexão, por exemplo, de boa parte das ciências sociais e da historiografia dos anos 1940 e 1950 nas Américas. Referimo-nos aos famosos binômios, do tipo "antigo x moderno"; "campo $x$ cidade"; "desenvolvimento $x$ subdesenvolvimento"; "atraso x progresso"; "colônias de exploração x colônias de povoamento"; etc. Mostra-nos, ao invés disso, como, mesmo nas ditas colônias de povoamento, os colonos que compunham a população dominante podiam ter sido eles próprios colonizadores na suas relações para com as populações indigenas vizinhas e que podiam, ao mesmo tempo, também experimentar a situação de colonizados na relação que estabeleciam com as sociedades metropolitanas, às quais se encontravam vinculados?

Tal relativização das relações de poder (ou seja, a eventual troca de papéis e a simultâneidade das relações) implicava a existência de autoridades diversas, as quais deveriam ser, na maioria das vezes, negociadas. Greene afirma que em quase todo tipo de relação estabelecida entre dominantes e dominados (mesmo aquela entre senhores e escravos), havia sempre espaço para manobras. Mais ainda, diz que os mais poderosos (os 
power-ful) com freqüência consideravam aconselhável negociar sua autoridade com os dominados, os considerados "power-less"8. Não está exatamente em discussão o quanto esta preponderância de poder podia ou não ser negociada (o que variou em cada caso). Entretanto, é inegável a existência da possibilidade de sua negociação.

Tal possibilidade faz-nos pensar em como os colonos puderam ser bem sucedidos nisso, isto é, como expressaram suas autoridades e com que propósito. A partir dessas considerações, o Autor passa a comentar, em seu artigo, as ações encaminhadas pelos colonos para transformar uma América indigena em uma efetiva "América britânica colonial" ("colonial British America").

Antes de desenvolvermos esse raciocinio de Greene, cabe mencionarmos a percepção de uma certa confusão nas suas observações a respeito da América Espanhola. Ainda que de forma breve, ao falar desta última América ${ }^{9}$, o Autor menciona as populações autóctones que permaneceram "de fora" das áreas de controle dos colonos (areas of settler control) e resistentes às suas influências. Dito com as suas próprias palavras: "(os grupos indigenas) certamente não faziam parte dos colonizados, pelo menos não antes do seu deslocamento e subjugação". E, completa: "O mesmo se aplica às repúblicas indigenas de governo autônomo da América hispânica, que existiam paralelamente às repúblicas de espanhóis sem [grifo meu] ficarem sob controle político imediato dos povoadores espanhóis". As duas afirmações soam bastante contraditórias.

Primeiro, porque, como bem sabemos, na América espanhola, a possibilidade da população autóctone permanecer "de fora" da áreas de controle dos colonos foi extremamente dificultada. Com o fim da conquista, apenas indios desgarrados, fugidos de suas comunidades (que já haviam sido repartidas e submetidas ao tributo), e por isso tornados "párias" ou "forasteiros", poderiam ficar temporariamente fora de qualquer controle politico-administrativo direto dos colonos. De qualquer modo, essa ausência ou diminuição do controle - um fenômeno que se tornou cada vez mais freqüente ao longo do século XVIII, quando foi maior a desagregação das comunidades de indios submetidas ao reparto - sempre foi relativa. Na maioria dos casos, foi uma condição temporária, para além do fato de que o escapar ao controle político-administrativo direto estar longe de significar uma resistência às influências culturais do mundo dos colonos. Quatro séculos de colonização - acompanhados da expropriação de terras e do lento culturocídio a que foram sujeitas as populações autóctones - engendraram diferentes processos de "etnificação," e transformaram boa parte da população, inicialmente composta de europeus ou nativos, em "castas" ou mixed-blood, com freqüência depreciados pelas rigorosas legislações que ordenavam tanto a "república dos índios" como a "dos espanhóis". Dentro da jurisdição destas duas repúblicas e formalmente sob controle da Coroa, colonizadores, colonos e colonizados se encarregaram de negociar, permanentemente, as suas diferentes esferas de poder e autonomias locias. Mas, todos, sem exceção, se viram crescentemente "etnificados" e aculturados nessas "repúblicas". Retomaremos a discussão da negociação da autoridade mais adiante.

Voltando ao exemplo da América Inglesa, e preocupado em mostrar como se deu a transformação de uma América autóctone em uma "América britânica colonial", Greene trata das diferentes polities lá engendradas.

Em primeiro lugar, estabelece uma diferença entre os 3 tipos de colônias conquistadas: a) aquelas em que os colonos iniciais se retiraram com a chegada dos ingleses (Jamaica em 1655 e a Florida Oriental e Ocidental em 1763); b) aquelas em que a maioria dos colonos pioneiros permaneceu na área (Nova York, Nova Jersey e Delaware); e c) as de tipo mais excepcional, onde a imigração inglesa resultou, no início, bastante tênue (caso da Nova 
10

Ibidem.

11

Argumento este, defendido por ele em outros trabalhos - Cf. Jack P. Greene, "The American Revolution", American Historical Review, 105, no.1 (2000): 93-102 e Jack P. Greene, "State and National Identities in the Era of the American Revolution" in Nationalism in the New World (ed. by Don H. Doyle and Marco Antonio Pamplona). Athens: U. Georgia Press, 2006. pp 61-79.

12

Jack P. Greene, "Reformulando a identidade inglesa na América britânica colonial...", p.10.
Escócia, que permaneceu essencialmente francesa até 1748, ocasião em que se intensificou o povoamento britânico). Em todos os casos, porém, a "intenção de estabelecer sociedades provinciais a partir de um modelo inglês" ditou sempre a regra ${ }^{10}$. No primeiro tipo, apenas a ação dos colonos ingleses correu mais ou menos livre, sem grandes entraves; no segundo, a britanização em marcha resultou mais trabalhosa ou levou mais tempo; e no terceiro ela mostrou-se um tanto ou quanto rarefeita. 0 Quebec francês é um bom exemplo deste último caso.

Em suma, Greene afirma, no caso da América inglesa, como que praticamente todo o esforço de construção das novas polities que compreenderam o império esteve a cargo dos próprios colonos (mais do que da metrópole). Sublinha assim, mais uma vez, o caráter menos centralizado que marcou a formação do império inglês desde o seu início ${ }^{11}$. Diferentemente dos impérios espanhol e francês e do português, aquele não fora mantido junto tanto pela força. Ou seja, mesmo centralizado e pioneiro enquanto estado-nação moderno na Europa do século XVII, o império inglês foi, até 1707, um compósito caracterizado pelo governo indireto e autoridade fragmentada, teoria embrionária de soberania nacional e recursos fiscais e administrativos coercitivos considerados ainda limitados. A real e efetiva autoridade do império britânico transatlântico - do tipo da que viriamos a conhecer ao longo do século XVIII - veio a ser construída de "fora para dentro". Foi uma construção da periferia para o centro: (a) quer pela criação de novas arenas e poder local e individual, através das atividades dos participantes da empresa colonizadora nas Américas; (b) quer pela negociação dessas muitas novas arenas da periferia com os representantes metropolitanos do centro.

Outro aspecto importante constantemente lembrado por Greene - e que faz ressaltar mais ainda a diferença em relação aos impérios ibéricos - é o de que os colonos na América inglesa e seus agentes (magistrados e representantes) encontravam-se restringidos pela herança cultural e legal metropolitana. Essa herança era entendida como sendo o sistema similar de leis e governo, sistema este que Ihes permitia regulamentar relações sociais e econômicas e legislar sobre a aquisição e circulação da propriedade, sob a forma de terra, escravos e bens materiais.

Greene estabelece uma intima relação entre a justificativa do comportamento dos colonos em relação aos povos indígenas locais e aos africanos e as estórias que construíram para explicar a "nobre empresa" de translado da civilização européia para as novas terras - ou, o que chamou de "sentido mais amplo de suas vidas". A convicção que guiou a lógica da expansão do povoamento ao longo de todo o período colonial, a medida que os colonos se apressaram em estabelecer novas unidades políticas e levar a lei e 0 governo aonde quer que fosse, baseava-se na intenção de criar "postos avançados da civilidade européia," ou "a transformação de territórios até então explorados de maneira imprópria em estados civilizados"12.

A discussão que se segue é a sobre o que fizeram os colonos inglêses/ britânicos para tornar mais inglesas ou britânicas as suas novas sociedades políticas. Numa alusão ao trabalho de Erik Erikson, dos idos de 1950s, sobre o "caráter" do lugar e do povo em diferentes seções do país e recuperando algumas de suas próprias pesquisas passadas, Greene compara o que chamou de "identidades corporativas cambiantes" em três colônias de plantations nos séculos XVII e XVIII - Virginia, Jamaica e Carolina do Sul - e em Barbados. Discute o que essas colônias compartilhavam (a mesma herança social, cultural, politica e legal britânica e a religião do protestantismo) e o que as diferenciava. A identidade de cada uma delas vem definida, 
13

Idem, p.11.

14

Idem, p.13.

15

Idem, p.14. Cabe associar essa discussão empreendida por Greene aos trabalhos de Anthony Smith sobre a "naturalização" de identidades coletivas, corporativas e nacionais e a "nacionalização" da natureza. Veja-se a respeito Anthony Smith, Ethnic Origins of Nations (1986), especialmente o capitulo 8, e também o seu excelente artigo "Conmemorando a los muertos, inspirando a los vivos. Mapas recuerdos y moralejas en la recreación de las identidades nacionales", publicado na Revista Mexicana de Sociología, Año LX, n 1, Enero-Marzo, 1998. pp 61-80. aqui, como um modo particular "como indivíduos, ou coletividades, identificam-se a si mesmos e aos outros, e como os outros os identificam". 0 tipo de identidade que the interessa (posto que há sempre vários niveis desta: indivíduo, familia, grupos de parentesco, congregação, província, nação etc) é a "identidade corporativa das colônias" - o produto de gerações, de vivência e história comuns, atuando num mesmo governo civil ("polity").13

A estratégia buscada para detectar essa identidade corporativa foi o estudo de 2 tipos de fontes relativas a esses 4 espaços coloniais: (a) as leis que essas sociedades fizeram para si próprias e (b) a literatura discursiva dos contemporâneos sobre si próprios.

As leis são particularmente importantes, pois permitem-nos perceber mudanças ao longo do tempo. Também revelam os valores de um povo dito independente e virtuoso vis a vis aos comportamentos dos demais segmentos da população que, em alguma medida, propiciaram ou incitaram a existência de tais leis.

Mas é da literatura, e não das leis, que Greene mais se ocupa nesse seu artigo. Numa primeira fase da formação de identidade, diz-nos ele, teria predominado uma literatura concentrada na descrição dos espaços físicos da colônia. Eram relatos de viagem, às vezes disfarçados de histórias e panfletos de propaganda, com o objetivo de valorizar e descrever para os leitores metropolitanos a natureza da terra, a vegatação, os povos indígenas, os rios, a vida selvagem, o clima etc. Constava desse tipo de literatura a especulação sobre os produtos que poderiam vir a ser produzidos na colônia, em que medida tais produtos atenderiam a demanda européia e como esse espaço físico tão peculiar viria a ser adaptado aos desígnios ingleses.

Numa segunda fase, a literatura dos contemporâneos assumiria mais a forma de estórias ou relatos sobre o ocorrido e seu foco se deslocaria para uma avaliação do que exatamente os colonos haviam feito ou deixado de fazer para transformar os espaços físicos ocupados em lugares "reconhecidamente ingleses". Enfim, a literatura versava sobre as transfomações sociais, econômicas, culturais e políticas que tinham sido implementadas, até aquele momento, pela população de colonos, creoles ou imigrantes assimilados.

Teria havido, também, no dizer de Jack Greene, uma terceira fase, estágio ou momento da formação da identidade. Uma em que a ênfase recairia numa espécie de articulação da identidade emergente específica da colônia com os seus povos (particularmente com aqueles tidos como livres). Ou seja, nesses espaços físicos especificos, a partir de experiências comuns ou de histórias locais que enfatizavam, todas, o caráter das sociedades neles desenvolvidas, teria ocorrido uma reformulação da idéia de identidade inglesa ("Englishness") - reformulação essa que melhor se ajustava às condições encontradas e criadas em cada uma dessas províncias ${ }^{14}$.

É nesse sentido que Greene chama a atenção para o fato de escritores contemporâneos defenderem a idéia de que uma dada colônia havia se tornado uma entidade corporativa distinta de qualquer outra identidade corporativa do mundo britânico. Mais ainda, de reclamarem que seus residentes haviam se tornado um POVO distinto e particular, diferente de qualquer POVO inglês que habitasse qualquer outro lugar. $E_{1}$ se algum dia foram todos (ou a maioria) Britânicos, eles eram, com efeito, agora, "variantes Virginianas, Barbadianas, Jamaicanas ou Carolinianas do Sul, do cidadão ou da condição de inglês" 15.

\section{Valores britânicos e identidades coloniais.}

A ênfase na distinção ou particularidade provincial não implicou a rejeição dos modelos e padrões ingleses/britânicos. A manutenção da condição de inglês ou a contínua valoração da idéia de Englishness - por exemplo, 
16

Jack P. Greene, "Reformulando a identidade inglesa na América britânica colonial...", p.16.

17

Idem, p.15 por meio da alusão à experiência dos seus antepassados, fundadores e desbravadores, construtores de identidades britânicas no Novo Mundo - puderam ser mantidas. Ademais, dar continuidade a esse vínculo com a Grã-Bretanha (partilhar das liberdades inglesas, em suma), os mantinha diferenciados dos muitos "outros" na colônia - dos povos indigenas da Virgínia e da Carolina do Sul, dos povos africanos em todas as 4 colônias tratadas e, também, dos povos europeus que se encontravam submetidos a outros impérios. Os colonos viam nisso uma profunda relação de compromisso para com as formas de governo consensual e o sistema de leis inglesas, com a ênfase na santidade da propriedade privada e no reino da Lei; e para com o protestantismo e o comércio, que há muito os mantinham fortemente vinculados à sociedade metropolitana.

Por isso Greene nos fala de 2 tipos distintos, ainda que simultâneos, de modelos que se encontrariam em ação entre os colonos - um normativo e outro comparativo. 0 primeiro, era o da exemplaridade. Cabia-Ihe fornecer aos colonos os principais padrões ou referências para que pudessem pensar a si próprios, dando. Dava-Ihes os tijolos que deveriam usar na construção de sua própria identidade. 0 segundo modelo era o que Ihes permitia identificar o que não eram, não queriam, ou não podiam ser - isto é, o que os opunha às populações ditas bárbaras ou selvagens, a todos os "estrangeiros" ao seu grupo. Apresentava os ameríndios e os africanos como bastante distanciados dos "britânicos livres ou independentes" que podiam se beneficiar da existência de direitos tradicionais e proteções legais ${ }^{16}$.

Vemos aqui outra percepção pouco trabalhada por Greene que pode sugerir interpretações simplificadas demais. Na análise proposta, o Autor acaba deixando de lado as várias tensões e contradições vivenciadas no diaa-dia pela população dos colonos, ao longo desse processo de construção de identidade. Ou seja, os dois modelos de certo não funcionam harmonicamente e, podemos dizer, costumam entrar em crise com freqüência. Assim, o Autor parece ignorar, aqui, os inúmeros relatos das autoridades coloniais sobre o medo de barbarização dos colonos. 0 receio de que suas populações pudessem ser deixadas à mercê da wilderness, era partilhado em outras colônias. Era preciso impedir que, longe da civitas, os colonos, tendencialmente "gente de bem", acabassem por, naturalmente, se afastar das normas. Isso exigiu medidas de vigilância permanente, por vezes de violência, por parte dos seus pares e especialmente por parte de suas igrejas, encarregadas de garantir a contínua submissão aos poderes secular e divino. Em suma, uma tal crise era constante e as tensões vivenciadas efetivamente conduziram a resoluções que podiam passar, como dito no início do trabalho, tanto pelo conflito, como pela negociação. Não era tão certo, pois, que no caminho trilhado pelos colonos, apenas os dois modelos - o normativo e 0 comparativo - contassem, com sinal de mais ou de menos.

Uma segunda questão é a do impulso anglicizante mencionado por Greene a partir do século XVIIII7 - a sua contribuição quer para o acirramento da identidade colonial, quer para a valoração positiva da idéia de Englishness, ao mesmo tempo.

Cabe lembrar que desde a Paz de Utrecht (1713), com a redefinição do equilibrio europeu e com as indenizações feitas pelo império espanhol (das quais muito se beneficiou a Grã-Bretanha: com o direito de asiento pelos próximos 30 anos - o que the garantiu o monopólio do tráfico de escravos para todo o império espanhol, além do envio anual de um navio com 500 toneladas de mercadorias para serem negociadas nas colônias espanholas do Novo Mundo), o crescimento das comunicações e os vínculos comerciais entre as colônias americanas e a Grã-Bretanha aumentaram consideravelmente. A partir de 1740, estes vínculos se expandiram mais ainda, acompa- 
18

Idem, p.16.

19

Idem, pp.16-17.

20

J. G. A. Pocock, Virtue, Commerce and History: Essays on Political Thought and History,

Chiefly in the Eighteenth Century (Cambridge: Cambridge University Press, 1985) e Bernard Bailyn, As Origens Ideológicas da Revolução Americana (SP: Edusc, 2003). nhando o desdobramento das guerras imperiais contra a França e a Espanha católicas, ditas despóticas, entre 1739 e 1763. É nesse periodo, afirma Jack Greene, que o novo impulso anglicizante teria tomado conta do patriotismo e nacionalismo britânico colonial.

Expliquemos. Greene se refere aos padrões ingleses de ocupação da terra, de organização econômica e social, de práticas culturais e políticas, legais e religiosas e à própria lingua inglesa, enquanto lingua da autoridade - todos teriam sido revividos com bastante intensidade no periodo.

Com a conclusão da Guerra dos Sete Anos e, mais especificamente, nos anos compreendidos entre 1764 e 1776, circunstâncias outras interferiram, levando os colonos ressentidos a reivindicar mais uma vez o reconhecimento metropolitano de sua identidade como britânicos nascidos livres e como protestantes. A resistência colonial às medidas repressivas da Coroa britânica aumentou no período. Mas, ela ocorreu a partir do mesmo imaginário político comum, ainda que já apropriado diferentemente pelos colonos britânicos. Como bem afirma Greene, "Britânico, portanto, era uma categoria dotada de várias subcategorias"18 - ser um britânico natural da Virginia era diferente de ser da Pensilvânia ou de Rhode Island. Mas, apenas a condição de britânicos poderia Ihes permitir sentir-se comprometidos com formas de governo consensual e com o reino da Lei. A resistência foi feita, então, a partir de uma dupla demanda por parte dos colonos: a da sua identidade enquanto britânicos e a da sua identidade provincial; uma geral, outra particular, mais sólida e desenvolvida, que thes permitiu sentir-se "confortáveis e orgulhosos" e os tornou, no dizer de Greene, "extraordinariamente defensivos"19. Assim, a sua explicação para o fato de os colonos em 1776 não mais se mostrarem hesitantes em renunciar à identidade britânica passa por esta valorização das identidades provinciais fortalecidas, a partir do impulso anglicizante mencionado (por mais que isso possa parecer contraditório). Em outras palavras, as identidades provinciais viriam, já há algum tempo, resignificando os vários elementos que definiam a identidade britânica - a ênfase no protestantismo, na liberdade, no reino da Lei, no governo com consentimento dos governados, na civilidade e no comércio. Como resumiu Greene: "Long before, in most cases, they had found ways to fold their British identity... into their provincial identities." E, foi por isso que tais identidades provinciais Ihes deram segurança, Ihes permitiram renunciar à associação com a Grã-Bretanha e transformar as colônias em "republican polities", sem o medo de perderem a antiga (e psicologicamente muito importante - lembra-nos Greene) percepção de si próprios como povos protestantes nascidos livres e herdeiros legítimos das tradições britânicas do governo das leis, com o consentimento dos governados.

Dai ousar Greene dizer que isso acabou tornando a nossa primeira revolução atlântica, a Revolução Americana, ao mesmo tempo radical e conservadora - ou seja, a fez responsável pelo desenvolvimento de uma cultura política particular, que enfatizava elementos quer da tradição do humanismo cívico, quer do liberalismo novo e radical, numa linguagem política crescentemente resignificada.

Talvez isso explique, como anteriormente já havia sugerido J. G. A. Pocock em sua obra20, por que foi possivel na linguagem republicana setecentista desenvolvida na América, por um Thomas Paine, por exemplo, reunir em uma mesma proposta termos inicialmente considerados opostos, como a virtude e o comércio. Isto é, ao apresentá-los não mais em oposição, mas como complementares, obras como o Senso Comum, permitiriam uma nova e bastante particular apropriação do ideário político republicano clássico - em tudo muito diferente da que era vivenciada na metrópole com o uso da mesma linguagem política, ao longo de todo o século XVIII. 
21

Ver a respeito o livro de Greene, The Intellectual Construction of America (Chapel Hill, 1993); e os seus seguintes artigos: "The American Revolution," American Historical Review 105, no 1 (2000) 93-102; e "State and National Identities in the Era of Revolution" in Doyle and Pamplona, eds., Nationalism in the New World (U. Georgia press, 2006), pp 61-79.

22

Para maiores informações sobre o funcionamento do sistema político-partidário do período veja-se Marco Pamplona, Revoltas, Repúblicas e Cidadania (RJ: Record, 2003), cap 3.
IV. A sobrevivência das identidades corporativas herdadas da colônia.

Em sua análise, Jack Greene afirma que o desmembramento do Império britânico nas Américas não impediu sobrevivências ou continuidades das identidades provinciais ali herdadas durante um primeiro periodo dito nacional - a saber, o que marcou os anos de 1780s a 1830 s.

Com esta afirmação, o autor recupera algumas de suas teses mais clássicas, já desenvolvidas ao longo de vários trabalhos prévios. Primeiramente, (a) a de que a Revolução Americana foi em grande medida uma "Revolução Britânica"; em segundo lugar, (b) a de que há grandes continuidades entre o período colonial e o nacional, não se devendo por isso, superestimar o seu caráter revolucionário; e, em terceiro, (c) a de que a Revolução foi um primeiro passo de um processo ainda incompleto de desmantelamento das estruturas imperiais criadas na época moderna ${ }^{21}$.

Greene reforça todas essas idéias no texto em discussão, especialmente quando apresenta os primeiros anos republicanos como profundamente marcados pela política dos estados. Tal percepção do peso da política dos estados faz sentido, no nosso entendimento, quando referida apenas a um primeiro momento da vida republicana - de 1787 a meados da década de 1830 -, quando as antigas "provincial state identities" continuaram vigorando e se mostraram extremamente fortes. Elas dominaram a dinâmica da federação durante o período do chamado " 1 0 sistema de partidos" e também durante parte dos anos compreendidos pelo " 20 sistema de partidos. ${ }^{22 \text { " Já }}$ a partir da década de 1840, uma vez tornada mais crucial a discussão em torno da anexação dos novos territórios, as antigas "provincial state identities" não mais tiveram tanto controle do jogo político ou perderam sua capacidade de negociar. As tentativas de acordo ensaiadas acabaram fracassando -- e o surgimento de um crescente seccionalismo tomou conta do cenário político, abalando e transformando algumas dessas identidades estatais prévias, até mostrar-se triunfante ao final. 0 Wilmot Proviso de 1846 e o estabelecimento do Compromisso de 1850 são a expressão maior dessa vitória de identidades seccionais mais fortes, ou subnacionalismos em construção, em especial no que se refere ao Sul.

Com a primeira medida, tentou-se legislar sobre a situação criada com o fim da guerra do Texas, de modo a atender interesses crescentemente em oposição - os dos estados do Sul e os do Norte. A provisão encaminhada pelo Senador Wilmot, um Democrata nortista, em 1846, propunha a proibição da escravidão em qualquer território ao norte do México. Apoiada pelo Partido do Solo Livre, ela foi, entretanto, ferrenhamente combatida pelos Democratas sulistas.

Quando da negociação do Compromisso de 1850, a tensão entre Norte e Sul reapareceu com mais força. À ocasião, 5 principais pontos foram negociados, em torno das seguintes perguntas: 1) como a recém-comprada California entraria para a Federação, se como estado livre ou escravista?; 2) qual seria o status, nesse mesmo sentido, dos demais territórios tomados (Novo México, Utah e Arizona)? ; 3) a quem caberia pagar a dívida do Texas, um estado sabidamente pró-escravidão?; 4) qual deveria ser o status da escravidão no Distrito de Columbia, a capital?; e 5) deveriam todos os estados obedecer à cláusula constitucional que obrigava a devolução do "escravo fugitivo"?

Ao final, o Compromisso teve de ser votado por partes. Acordou-se que: 1) a California entraria para a federação como estado livre; 2) nos demais territórios ocupados vigoraria o princípio da soberania popular - isto é, seus constituintes, uma vez formados, teriam 5 anos para decidir sobre que caminho seguir - o dos estados do Norte ou o do Sul; 3) no estado do Texas vigoraria a escravidão; 4) proibiu-se o tráfico interno de escravos, mas a escravidão continuou vigorando no D.C.; e 5) decidiu-se apenas que uma 
23

John Calhoun, representando a Carolina do Sul, convoca, a seguir, uma primeira reunião de estados sulistas em Nashville, para discutir a secessão.

24

Jack P. Greene, "Reformulando a identidade inglesa na América britânica colonial...", pp.18-19.

Idem, p.20.

nova lei será encaminhada a respeito da obrigatoriedade, ou não, de devolução dos escravos fugitivos (desde 1842 tida como responsabilidade federal) aos seus estados de origem. 0 Sul leu esta última decisão como apenas o reconhecimento formal dos "direitos" da escravidão, o que anteciparia a sua escolha pela secessão 23 .

Assim, se para o periodo até 1830s não resta dúvida quanto ao caráter embrionário e superficial da identidade nacional Americana, fazendo com que - como defende Greene - a centralidade da identidade dos estados no compósito nacional permaneça inabalável; achamos que o mesmo não pode ser inferido a partir da disputa pelos novos territórios - o grande problema que marcou as duas décadas seguintes. Foi a partir dai que dois projetos de estado-nação construídos a partir das identidades seccionais em expansão no período, passaram a dominar a dinâmica política da federação.

Finalmente, um último comentário sobre um ponto não menos importante anunciado por Greene. Referimo-nos à sua visão a respeito de uma continuidade do processo de colonização (e povoamento) nas novas areas, isto é, no Oeste. Diz-nos o Autor que: :

"enxames de povoadores colocavam novas regiões sob seu controle e, nesse movimento, expulsavam ou confinavam a enclaves indesejáveis milhares de indigenas, fazendo uso intenso, onde quer que fosselegalmente possivel e rentável, de mão-de-obra afro-descendente". 24

Greene considera esse processo ocorrendo no primeiro periodo nacional também uma extensão da expansão colonial. A diferença residiria no fato dessa extensão vir presidida agora por um estado americano fraco, ao invés de um estado britânico fraco.

Greene afirma que uma boa parte das ações deste empreendimento teria ficado a cargo dos próprios colonos, como no periodo precedente. Por isso as novas polities em construção diferiram tanto umas das outras, tais como as colonias diferiam entre si no passado.

A ênfase dada por Greene a esses traços de continuidade, em verdade, mostra-se de grande valia aqui. Permite-nos combater a retórica excessiva sobre um destino nacional Americano que ainda predomina em muitas das análises sobre o período independente e que simplesmente abundam na historiografia produzida naquele país. Greene propõe, ao invés disso, uma história federal bem diferente, com uma narrativa menos nationally-focused, ou uma menos text-book driven history.

Defende, enfim, uma história mais complexa, mais desafiante, com sinteses talvez mais dificeis ou mesmo impossiveis. Trata-se de ver a dita experiência nacional, ao menos nos seus inícios, mais como uma coleção de variadas experiências locais ou, quando muito, como um amálgama de polities variadas, similares, porém sempre distintas entre si. ${ }^{25}$

Concluimos dizendo que, neste cenário, a discussão da negociação de autoridades - presente desde o início da reflexão - ganha enorme força e sentido. Trata-se menos de valorizar movimentos centripetos ou centrifugos, e mais de identificar as freqüentes articulações, subordinações e dominações que, em uma ou em outra direção, efetivamente põem em contato diferentes loci de poder, e de não menos diferentes grandezas. 